\title{
Physiological Tools for Evaluating Growth Status of Migrating Salmon
}

\author{
Munetaka Shimizu \\ Faculty of Fisheries Sciences, Hokkaido University, 3-1-1, Minato, Hakodate, Hokkaido 041-8611, Japan
}

Keywords: growth indices, Insulin-like growth factor (IGF)-I, IGF-binding proteins

Growth-dependent mortality of juvenile salmon during the early phase of their marine life has been an active area of research. Although the exact timing and the extent of growth-dependent mortality are not clear (Beacham et al. 2017), the general belief is that large and/or fast-growing juveniles have a better chance to survive and will be recruited to the stock (Beamish and Mahnken 2001). Monitoring growth status of out-migrating juveniles is therefore of particular importance. However, a direct measure of growth of individual fish requires marking and recapture of the same individuals, which is extremely difficult to conduct on free-swimming salmon. Instead, indirect methods are often used to evaluate/estimate growth. Among them, scales and otoliths are useful to reconstruct past growth patterns and habitats. However, they may not provide information on the recent/current growth rate. Biochemical growth indices such as muscle RNA/DNA ratio have been used to monitor recent/current growth, although their validity is somewhat incomplete (Johnson et al. 2002). Ideally, growth indices should be directly involved in the growth process and not a result of growth (Couture et al. 1998).

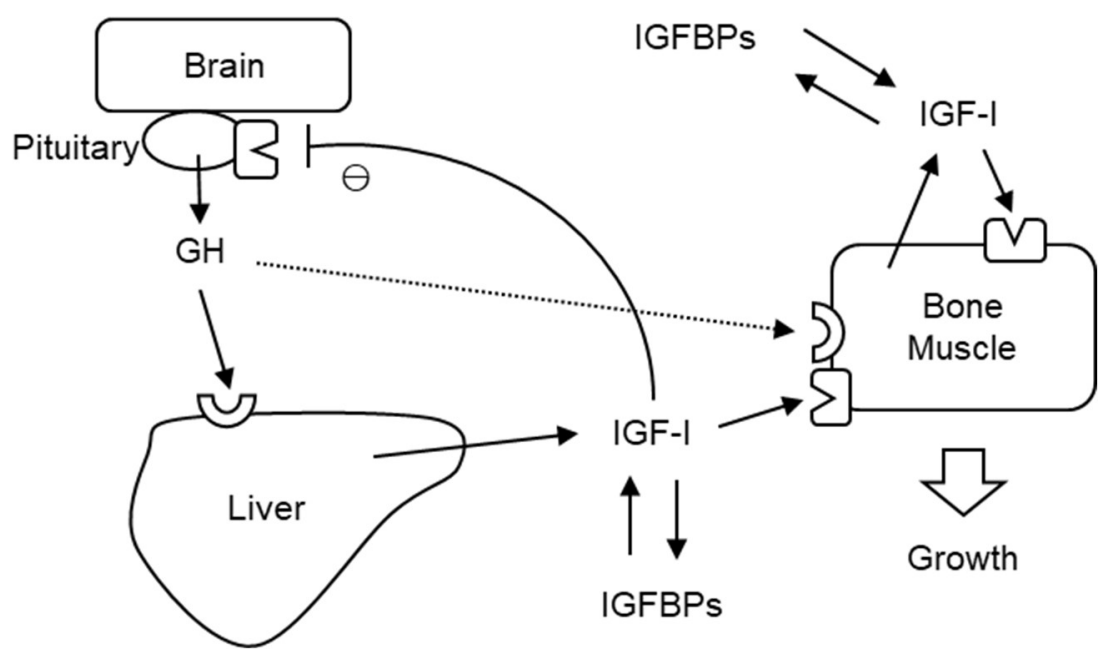

Fig. 1. The growth hormone (GH)insulin-like growth factor (IGF)-I-IGFbinding protein (IGFBP) system regulating fish growth.

We focus on hormones and proteins involved in growth regulation to evaluate current growth status because they provide a semi-quantitative estimation of growth rate and mechanistic interpretation. The growth of vertebrates including salmon is mainly regulated by the growth hormone (GH) and insulin-like growth factor (IGF)-I system (Fig. 1). In this system, GH is secreted from the pituitary gland and can promote growth by directly acting on the target tissues such as muscle and bone, or indirectly through stimulating hepatic production of IGF-I. IGF-I is then secreted into the bloodstream, delivered to the target tissues and mediates the growth-promoting action of GH. Circulating IGF-I has been reported to be correlated with individual growth rate in salmon and proposed as an index of salmon growth (Beckman et al. 2004a, b; Beckman 2011).

Mechanistically, the activity of IGF-I is tightly regulated by IGF-binding proteins (IGFBPs). IGFBPs are capable of inhibiting and potentiating IGF-I action by controlling its availability to the receptor. Thus, IGFBPs are important components of the GH-IGF-I system. There are six types of IGFBPs, termed IGFBP 1 to 6 , identified in mammals. In teleosts, two subtypes ("a" and "b") of each member of IGFBPs are generally present due to an extra round of whole genome duplication in this lineage.

In salmon circulation, at least three IGFBPs are detected. We have identified these three IGFBPs as IGFBP$1 \mathrm{a}, 1 \mathrm{~b}$, and 2b, respectively (Shimizu and Dickhoff 2017). Rearing experiments using post-smolt coho salmon held in freshwater revealed that circulating IGFBP-2b levels were high in well-fed fish and positively correlated with individual growth rate (Beckman et al. 2004a, b). These characteristics are similar to those of IGF-I and there is a positive correlation between circulating IGF-I and IGFBP-2 $b$ levels, suggesting that IGFBP- $2 b$ is a major carrier of circulating IGF-I. In contrast, IGFBP-1a and $-1 \mathrm{~b}$ are induced under catabolic conditions such as fasting and stress, and inversely correlated with individual growth rate (Shimizu et al. 2006, 2011; Kaneko et al. 2020). It is of note

All correspondence should be addressed to M. Shimizu. 
that IGFBP-1b appears to be more sensitive to fasting than IGFBP-1a in masu salmon (Kawaguchi et al. 2013). These findings led us to propose that circulating IGF-I and IGFBP- $1 \mathrm{~b}$ are positive and inverse indices of salmon growth, respectively (Fig. 2).
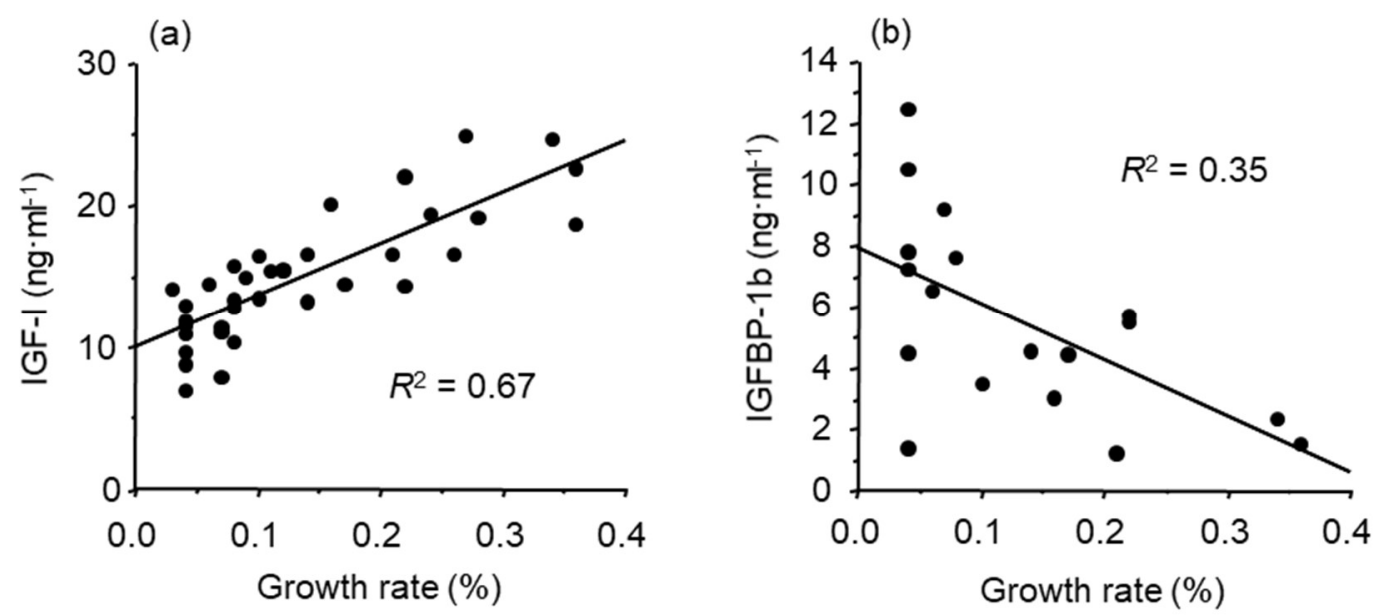

Fig. 2. Correlations of circulating insulin-like growth factor (IGF)-I and IGF-binding protein (IGFBP)-1b with individual growth rate of post-smolt coho salmon in freshwater. Data are from Beckman et al. (2004a) and Shimizu et al. (2006).

We are currently working on chum salmon because of its importance in Japan and recent declines in return numbers. Rearing experiments using juvenile chum salmon held in seawater confirmed that circulating IGF-I and IGFBP-1b levels were positively and negatively correlated with individual growth rate, respectively (Kaneko et al. 2019b), confirming their applicability to salmonids in general. Using these physiological indices, we have been conducting field surveys through a collaboration with Hokkaido Research Organization and the Abashiri Fisheries Cooperative to evaluate growth status of out-migrating juvenile chum salmon in the Abashiri area, northeastern Hokkaido, Japan. Profiles of serum IGF-I and IGFBP-1b levels suggested that small, slow-growing juveniles stayed at the estuary throughout the out-migration season and might suffer growth-dependent mortality (Kaneko et al. 2015). On the other hand, serum IGF-I levels in fish in nearshore were high, suggesting that they were activating growth while moving to offshore.

In order to further assess the utility of the growth indices for free-swimming salmon, we conducted a "biological validation" by measuring plasma samples of young coho salmon caught at a region where growth retardation was expected (Kaneko et al. 2019a). Coho salmon plasma were obtained by a field survey conducted by Canadian and US researchers along the Strait of Georgia and surrounding waters, British Columbia, Canada (Journey et al. 2018). The Johnstone Strait is thought to be a poor feeding ground for salmon due to its strongly tidally mixed waters. Our assumption was that IGF-I and IGFBP-1b levels were low and high, respectively, in coho salmon in Johnston Strait. However, plasma IGF-I levels in fish from the Johnstone Strait were not low, being comparable to those from other regions (Journey et al. 2018). It is possible that the fluctuation of environmental factors, such as water temperature, might disturb the growth-IGF-I relationship. On the other hand, plasma IGFBP$1 \mathrm{~b}$ levels were highest at the Johnstone Strait as expected (Kaneko et al. 2019a). These results showed that responses to the growth indices are sometimes contradictory. However, when we calculated the molar ratio of IGF-I to IGFBP-1b, which is theoretically a fraction of IGF-I available for growth promotion, it was lowest in fish from Johnstone Strait (Kaneko et al. 2019a). Thus, combining multiple growth indices may stabilize the accuracy of growth evaluation. Although more validation for IGF-I and IGFBP-1b is necessary to utilize them as growth indices for migrating salmon, the results so far are supportive and warrant further research.

In summary, we propose that IGF-I and IGFBP-1b are useful physiological tools to assess the recent/current growth status of salmon and a good complement to other growth indices such as scales, otoliths, and RNA/DNA ratio. An advantage of these endocrine factors is that they provide a mechanistic basis of growth alteration. Rearing experiments using the physiological tools should help disentangle factors influencing growth and thus assess the timing and degree of the possible growth-dependent mortality of juvenile/young salmon. 


\section{REFERENCES}

Beacham, T.D., C.M. Neville, S. Tucker, and M. Trudel. 2017. Is there evidence for biologically significant sizeselective mortality of coho salmon during the first winter of marine residence? Trans. Am. Fish. Soc. 146: 395-407.

Beamish, R.J., and C. Mahnken. 2001. A critical size and period hypothesis to explain natural regulation of salmon abundance and the linkage to climate and climate change. Prog. Oceanogr. 49: 423-437.

Beckman, B.R. 2011. Perspectives on concordant and discordant relations between insulin-like growth factor 1 (IGF1) and growth in fishes. Gen. Comp. Endocrinol. 170: 233-252.

Beckman, B.R., M. Shimizu, B.A. Gadberry, and K.A. Cooper. 2004a. Response of the somatotropic axis of juvenile coho salmon to alterations in plane of nutrition with an analysis of the relationships among growth rate and circulating IGF-I and $41 \mathrm{kDa}$ IGFBP. Gen. Comp. Endocrinol. 135: 334-344.

Beckman, B.R., M. Shimizu, B.A. Gadberry, P.J. Parkins, and K.A. Cooper. 2004b. The effect of temperature change on the relations among plasma IGF-I, 41-kDa IGFBP, and growth rate in postsmolt coho salmon. Aquaculture 241: 601-619.

Couture, P., J.D. Dutil, and H. Guderley. 1998. Biochemical correlates of growth and condition in juvenile Atlantic cod (Gadus morhua) from Newfoundland. Can. J. Fish. Aquat. Sci. 55: 1591-1598.

Johnson, M.W., J.R. Rooker, D.M. Gatlin, and G.J. Holt. 2002. Effects of variable ration levels on direct and indirect measures of growth in juvenile red drum (Sciaenops ocellatus). J. Exp. Mar. Biol. Ecol. 274: 141157.

Journey, M.L., M. Trudel, G. Young, and B.R. Beckman. 2018. Evidence for depressed growth of juvenile pacific salmon (Oncorhynchus) in Johnstone and Queen Charlotte Straits, British Columbia. Fish. Oceanogr. 27: 174-183.

Kaneko, N., N. Taniyama, Y. Inatani, Y. Nagano, M. Fujiwara, M. Torao, Y. Miyakoshi, and M. Shimizu. 2015. Circulating insulin-like growth factor I in juvenile chum salmon: relationship with growth rate and changes during downstream and coastal migration in northeastern Hokkaido, Japan. Fish Physiol. Biochem. 41: 9911003.

Kaneko, N., M.L. Journey, C.M. Neville, M. Trudel, B.R. Beckman, and M. Shimizu. 2019a. Utilization of an endocrine growth index, insulin-like growth factor binding protein (IGFBP)-1b, for postsmolt coho salmon in the Strait of Georgia, British Columbia, Canada. Fish Physiol. Biochem. 45: 1867-1878.

Kaneko, N., M. Torao, Y. Koshino, M. Fujiwara, Y. Miyakoshi, and M. Shimizu. 2019b. Evaluation of growth status using endocrine growth indices, insulin-like growth factor (IGF)-I and IGF-binding protein- $1 \mathrm{~b}$, in outmigrating juvenile chum salmon. Gen. Comp. Endocrinol. 274: 50-59.

Kaneko, N., T.O. Nilsen, H. Tanaka, A. Hara, and M. Shimizu. 2020. Intact rather than total circulating insulin-like growth factor binding protein-1a is a negative indicator of growth in masu salmon. Am. J. Physiol. Regul. Integr. Comp. Physiol. 318: R329-R337.

Kawaguchi, K., N. Kaneko, M. Fukuda, Y. Nakano, S. Kimura, A. Hara, and M. Shimizu. 2013. Responses of insulin-like growth factor (IGF)-I and two IGF-binding protein-1 subtypes to fasting and re-feeding, and their relationships with individual growth rates in yearling masu salmon (Oncorhynchus masou). Comp. Biochem. Physiol. A 165: 191-198.

Shimizu, M., and W.W. Dickhoff. 2017. Circulating insulin-like growth factor binding proteins in fish: their identities and physiological regulation. Gen. Comp. Endocrinol. 252: 150-161.

Shimizu, M., B.R. Beckman, A. Hara, and W.W. Dickhoff. 2006. Measurement of circulating salmon IGF binding protein-1: assay development, response to feeding ration and temperature, and relation to growth parameters. J. Endocrinol. 188: 101-110.

Shimizu, M., K. Kishimoto, T. Yamaguchi, Y. Nakano, A. Hara, and W.W. Dickhoff. 2011. Circulating salmon 28and 22-kDa insulin-like growth factor binding proteins (IGFBPs) are co-orthologs of IGFBP-1. Gen. Comp. Endocrinol.174: 97-106. 